\title{
POPULATION STRUCTURE OF ANOPHELES ARABIENSIS ON LA RÉUNION ISLAND, INDIAN OCEAN
}

\author{
ISABELLE MORLAIS,* ROMAIN GIROD, RICHARD HUNT, FRÉDÉRIC SIMARD, AND DIDIER FONTENILLE \\ Institut de Recherche pour le Développement (IRD), Yaoundé, Cameroon; Organisation de Coordination pour la lutte Contre les \\ Endémies en Afrique Centrale (OCEAC), Yaoundé, Cameroon; Service de Lutte Antivectorielle, Direction Régionale des Affaires \\ Sanitaires et Sociales de La Réunion, St Denis, La Réunion, France; School of Animal, Plant \& Environmental Sciences, University \\ of the Witwatersrand, Johannesburg, South Africa; Laboratoire de Lutte contre les Insectes Nuisibles (LIN), Institut de Recherche \\ pour le Développement (IRD), Montpellier, France
}

\begin{abstract}
Anopheles arabiensis, together with Anopheles gambiae sensu stricto, are the most important vectors of human malaria in sub-Saharan Africa. The malaria situation keeps worsening, with 1 to 3 million deaths a year, and alternative strategies are needed to decrease malaria transmission intensity. In this paper, we studied the population structure of An. arabiensis from three sample sites on the remote Indian Ocean island of La Réunion. Our results showed strong genetic structuring between An. arabiensis populations on La Réunion, indicating the presence of barriers to gene flow. Reasons for such a high genetic differentiation are discussed, including the role of intensive control measures that have maintained reduced effective population size as well as a putative genetic adaptation to the environment. This strong structuring situation on the island represents an ideal framework for the prospect of genetic-based control trials.
\end{abstract}

\section{INTRODUCTION}

Human malaria in sub-Saharan Africa is mainly transmitted by mosquito vectors of the Anopheles gambiae complex. Among the seven recognized species of this complex, ${ }^{1,2} A n$. gambiae sensu stricto and Anopheles arabiensis are the major disease vectors. An. arabiensis is the most widespread member of the An. gambiae complex, found throughout the Afrotropical region except in the Equatorial forest belt. ${ }^{3}$ Whereas An. gambiae s.s. is often the predominant vector when malaria transmission is at its highest level during the rainy season, An. arabiensis shows a greater tolerance to dry environments, and it is a major vector in Sahelian savannas. ${ }^{1}$

Today, the malaria situation is worsening in tropical Africa, the continent that bears the bulk of the world's malaria burden. ${ }^{4}$ For a number of sociological, economical, political as well as geographical and ecological reasons, control measures that allowed eradication of the disease in developed countries are difficult or impossible to implement and sustain in Afrotropical settings. ${ }^{5,6}$ Alternative strategies are therefore needed to overcome these limitations that challenge the control of malaria in Africa. Vector control is a cornerstone in the fight against malaria, and considerable research effort is currently devoted to exploring and designing innovative strategies to decrease malaria transmission intensity below the threshold necessary to maintain malaria endemicity.

Recent advances in molecular biology and vector genomics have renewed interest in genetically based control methods with the global aim of reducing vectors' ability to transmit the disease. Technical challenges are being gradually solved: stable germline transformation has been achieved in An. gambiae and other mosquito diseases vectors, ${ }^{7}$ candidate genes and genetic drive mechanisms are coming under scrutiny and evaluation, and there is no doubt that a transgenic mosquito, incapable of transmitting the disease, will soon be available. ${ }^{8,9}$ The biosafety and efficacy issues related to the use of this technology are becoming increasingly urgent to assess. For

* Address correspondence to Isabelle Morlais, Institut de Recherche pour le Développement (IRD), BP 1857, Yaoundé, Cameroon. E-mail: morlais@ird.fr this purpose, it has recently been argued that the first releases of genetically modified (malaria) mosquitoes should be done using sterile material. The Sterile Insect Technique (SIT) should primarily ensure reversibility of the process while allowing assessment of relevant population parameters and issues relating to factory production of competitive mosquitoes and their release in the wild to be assessed. ${ }^{10}$ Furthermore, lessons learned from previous mosquito releases and autocidal control have demonstrated that, to be effective, such attempts should be implemented in isolated areas such as islands to limit immigration from neighboring areas. ${ }^{11,12}$

In this paper, we describe the population structure of the malaria vector An. arabiensis on the remote island of $\mathrm{La}$ Réunion, located $700 \mathrm{~km}$ east of Madagascar in the Indian Ocean. Malaria was eradicated from the island after comprehensive malaria control programs implemented in the early 1950 s, including vector control and quinine prophylaxis. ${ }^{13}$ However, residual vector populations still thrive on the island requiring uninterrupted epidemiologic and entomological surveillance to prevent reemergence of the disease. ${ }^{14}$ An. arabiensis is the only member of the An. gambiae complex and the only potential malaria vector present on La Réunion. ${ }^{15}$ Using microsatellite markers, we investigated genetic variability and geographic differentiation within and between $A n$. arabiensis populations from three geographically isolated locations. We focused on La Réunion because the island represents an interesting putative site to undertake field trials using innovative vector control techniques, as described above. Understanding the population structure of the target population(s) is therefore of crucial importance, to assess feasibility of these strategies. Beyond simple description of the population structure and estimates of gene flow between geographical populations on the island, our results also provide baseline data to allow monitoring of the effect of new vector control methods, if these are to be implemented on $\mathrm{La}$ Réunion.

\section{EXPERIMENTAL PROCEDURES}

Study sites and mosquito sampling. La Réunion island $\left(21^{\circ} 55^{\prime} \mathrm{S}, 55^{\circ} 30^{\prime} \mathrm{N}\right)$ is an overseas French territory located in 
the Indian Ocean, c.a. $700 \mathrm{~km}$ from the east coast of Madagascar. It is a $2,512 \mathrm{~km}^{2}$ volcanic island with steep mountains, exposed to tropical oceanic climates. Humans and associated anthropophilic mosquito populations are mainly clustered along the sea shore, in discrete pockets of suitable habitat separated from one another by the spurs of the Piton des Neiges $(3,069 \mathrm{~m}$ above sea level) and the Piton de la Fournaise (2,632 $\mathrm{m}$ above sea level). Mosquitoes were collected at their larval stage during routine surveillance operations conducted by the technical team in charge of vector control from April to June 2003. They were sampled from GPS-referenced breeding sites in three locations on the northeast, southwest, and northwest coasts of the island (Figure 1) representing highly contrasted climatological features. The average annual rainfall for each location is given in Figure 1. To avoid sampling siblings, larvae were taken from isolated pools wherever possible. If more than one larva was taken from a single pool, widely different instars were picked. Larvae were individually preserved in $25-\mathrm{mL}$ glass containers and bred until emergence. Adults were identified using morphologic identification keys. ${ }^{1,16}$ Female specimens belonging to the An. gambiae complex were then transferred individually into $1.5-\mathrm{mL}$ centrifuge tubes containing a desiccant (Silicagel) and stored until laboratory processing.

DNA extraction and species identification. DNA was extracted from the whole mosquito as previously described. ${ }^{17}$ Species identification within the An. gambiae complex was performed according to the PCR protocol described in Scott and others. ${ }^{18}$ All mosquitoes were An. arabiensis.

Microsatellite genotyping. Microsatellite loci used in this study were selected from published An. gambiae sequence data. ${ }^{19,20}$ Ten loci were chosen based on prior evidence for successful amplification of An. arabiensis genomic DNA ${ }^{21-24}$ and on cytologic location spread over all three chromosomes. We used loci AgXH7, AgXH49 and AgXH53 on the X chromosome, loci Ag2H803, Ag2H26, Ag2H141, and Ag2H325 on the second chromosome, and loci 45C, Ag3H93, and Ag3H555 on the third chromosome (see Table 1 for more precise cytologic location of the loci). All microsatellite loci are dinucleotide repeat units. Primers were synthesized from Applera (Courtaboeuf, France); one primer for each set was

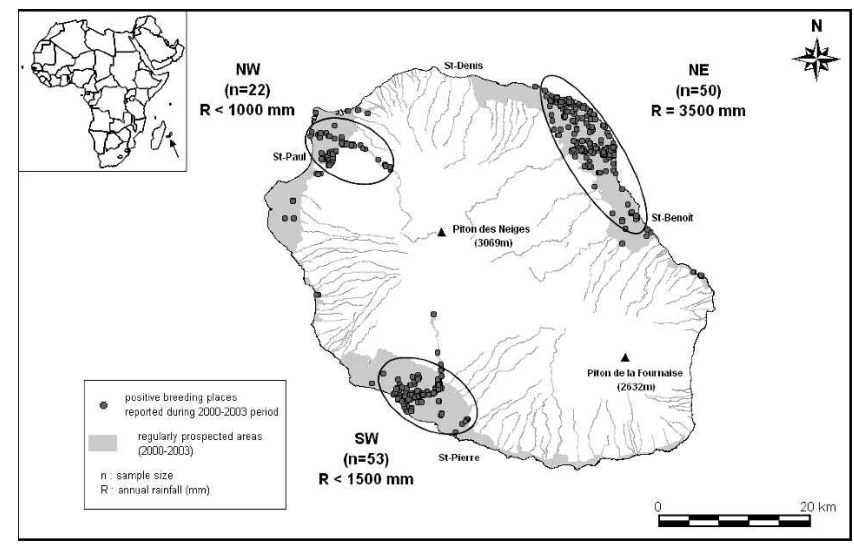

FIGURE 1. La Réunion island location and sampling sites. $\mathrm{n}$ indicates the number of specimens collected in each location; $\mathrm{R}$ represents the average annual rainfall. Dots represent An. arabiensis larval development sites recorded during routine entomological surveillance in 2000-2003.
TABLE 1

Genetic variability at 10 microsatellite loci and goodness of fit to Hardy-Weinberg equilibrium in natural populations of An. arabiensis from La Réunion island

\begin{tabular}{|c|c|c|c|c|c|}
\hline \multirow[b]{2}{*}{ Locus } & & \multicolumn{3}{|c|}{ Populations } & \multirow[b]{2}{*}{ Overall* } \\
\hline & & $\begin{array}{c}\mathrm{NE} \\
(2 \mathrm{n}=100)\end{array}$ & $\begin{array}{c}\text { SW } \\
(2 \mathrm{n}=106)\end{array}$ & $\begin{array}{c}\mathrm{NW} \\
(2 \mathrm{n}=44)\end{array}$ & \\
\hline \multirow{3}{*}{$\begin{array}{l}\mathrm{AgXH7} \\
(\mathrm{X}: 1 \mathrm{C}) \dagger\end{array}$} & No alleles & 2 & 1 & 2 & 3 \\
\hline & Ho & 0.020 & 0.000 & 0.273 & 0.056 \\
\hline & Fis & 0.000 & - & -0.135 & -0.021 \\
\hline \multirow{3}{*}{$\begin{array}{r}\mathrm{AgXH} 49 \\
(\mathrm{X}: 1 \mathrm{D})\end{array}$} & No alleles & 1 & 1 & 1 & 1 \\
\hline & Ho & 0.000 & 0.000 & 0.000 & 0.000 \\
\hline & Fis & - & - & - & - \\
\hline \multirow{3}{*}{$\begin{array}{r}\mathrm{AgXH53} \\
(\mathrm{X}: 3 \mathrm{D})\end{array}$} & No alleles & 2 & 2 & 2 & 2 \\
\hline & Ho & 0.480 & 0.096 & 0.455 & 0.315 \\
\hline & Fis & 0.036 & -0.041 & -0.024 & 0.327 \\
\hline \multirow{3}{*}{$\begin{array}{l}\mathrm{Ag} 2 \mathrm{H} 803 \\
\text { (II:7B) }\end{array}$} & No alleles & 2 & 2 & 2 & 2 \\
\hline & Ho & 0.540 & 0.538 & 0.409 & 0.516 \\
\hline & Fis & -0.148 & -0.093 & 0.041 & -0.029 \\
\hline \multirow{3}{*}{$\begin{array}{r}\mathrm{Ag} 2 \mathrm{H} 26 \\
(\mathrm{II}: 12)\end{array}$} & No alleles & 5 & 3 & 4 & 6 \\
\hline & Ho & 0.580 & 0.615 & 0.682 & 0.613 \\
\hline & Fis & -0.128 & 0.05 & 0.028 & 0.192 \\
\hline \multirow{3}{*}{$\begin{array}{l}\text { Ag2H141 } \\
\text { (II:2Rd) }\end{array}$} & No alleles & 2 & 3 & 2 & 3 \\
\hline & Ho & 0.460 & 0.547 & 0.455 & 0.496 \\
\hline & Fis & -0.065 & 0.120 & 0.273 & 0.052 \\
\hline \multirow{3}{*}{$\begin{array}{l}\mathrm{Ag} 2 \mathrm{H} 325 \\
\text { (II:23C-D) }\end{array}$} & No alleles & 1 & 1 & 1 & 1 \\
\hline & Ho & 0.000 & 0.000 & 0.000 & 0.000 \\
\hline & Fis & - & - & - & - \\
\hline \multirow{3}{*}{$\begin{array}{l}\text { 45C } \\
\qquad \text { (III:45C) }\end{array}$} & No alleles & 3 & 4 & 3 & 4 \\
\hline & Ho & 0.280 & 0.538 & 0.636 & 0.452 \\
\hline & Fis & 0.252 & 0.049 & -0.046 & 0.207 \\
\hline \multirow{3}{*}{$\begin{array}{l}\mathrm{Ag} 3 \mathrm{H} 93 \\
\text { (III:29A) }\end{array}$} & No alleles & 4 & 1 & 1 & $\overline{4}$ \\
\hline & Ho & 0.120 & 0.000 & 0.000 & 0.049 \\
\hline & Fis & -0.037 & - & - & -0.140 \\
\hline \multirow{3}{*}{$\begin{array}{l}\text { Ag3H555 } \\
\text { (III:35B) }\end{array}$} & No alleles & 4 & 4 & 4 & 4 \\
\hline & Ho & 0.580 & 0.528 & 0.500 & 0.544 \\
\hline & Fis & 0.129 & 0.070 & -0.024 & 0.176 \\
\hline \multirow{3}{*}{$\begin{array}{l}\text { Mean } \\
\text { across } \\
\text { all loci }\end{array}$} & No alleles & 2.6 & 2.2 & 2.2 & 3.0 \\
\hline & Ho & 0.306 & 0.286 & 0.341 & 0.304 \\
\hline & Fis & 0.010 & 0.042 & -0.044 & $\underline{0.151}$ \\
\hline
\end{tabular}

Fis values were estimated according to Weir and Cockerham. ${ }^{28}$ Bolded underlined values indicate statistical significance at $P<0.01$ after the sequential Bonferonni correction $\left(\mathrm{Holm}^{26}\right)$.

- , not computed because only one allele was detected in more than one copy.

*'All mosquitoes were considered as belonging to a single population.

All ber of chromosomes scored. No alleles, number of alleles. Ho, observed heterozygosity.

labeled with a $5^{\prime}$ fluorescent dye (i.e., NED, 6-FAM, HEX, PET, or VIC), chosen to allow multiplexing before automatic detection. For each primer set, the optimal annealing temperature was determined on an Eppendorf MasterCycler Gradient (Eppendorf AG, Hamburg, Germany). PCR reactions were carried out in a $25-\mu \mathrm{L}$ final volume containing 50 $\mathrm{mM}$ Tris- $\mathrm{HCl}, \mathrm{pH} 8.3,2.5 \mathrm{mM} \mathrm{MgCl} 2,50 \mathrm{mM} \mathrm{KCl}, 200 \mu \mathrm{M}$ of each dNTP (Eurogentec, Herstal, Belgium), 0.5 U of Taq polymerase (Qiagen, Courtaboeuf, France), 5 pmoles of each primer, and $5 \mathrm{ng}$ of DNA template. PCR runs were performed in a Gene Amp 9700 thermal cycler (Applied Biosystems, Foster City, CA) and included a first denaturation step at $95^{\circ} \mathrm{C}$ for 3 minutes, followed by 40 cycles at $95^{\circ} \mathrm{C}$ for 30 seconds, at the specific annealing temperature for 20 seconds and at $72^{\circ} \mathrm{C}$ for 10 seconds, and a final extension step at $72^{\circ} \mathrm{C}$ for 5 minutes. A $5-\mu \mathrm{L}$ aliquot of the PCR products was analyzed on a $2.5 \%$ agarose gel. PCR products were then multiplexed by mixing equal amounts of 3 to 4 amplified products. Mixtures were run on an ABI Prism 3100 sequencer, TAMRA dye was used as size standard. Genotypes were read using Genescan and Genotyper softwares (Applied Biosystems). 
Data analysis. Genetic diversity was assessed by calculating the observed heterozygosity $H_{\mathrm{O}}$, the number of alleles and allelic frequencies at each locus, for each mosquito population and overall. Tests for deviation from Hardy-Weinberg expectations and for linkage disequilibrium between loci were computed using the exact probability tests available in GENEPOP v3.3 software. ${ }^{25}$ The sequential Bonferroni procedure ${ }^{26}$ was applied to evaluate significance when multiple tests were performed. Genetic differentiation between populations was measured by $F$-statistics, ${ }^{27}$ computed according to Weir and Cockerham. ${ }^{28}$ Statistical significance of Fst estimates was assessed using ARLEQUIN software with permutation procedures. $^{29}$ Temporal variation in allelic frequencies was used to provide a quantitative estimate of the effective population size $(\mathrm{Ne})$ of the An. arabiensis population on La Réunion, using the traditional moment-based estimator described by Waples. ${ }^{30,31}$ For this purpose, we used genotypic data obtained by Simard and others ${ }^{22}$ from an An. arabiensis sample collected on La Réunion in February 1995 as our initial sampling point; four polymorphic microsatellite loci used in both studies (namely loci Ag2H141, Ag2H26, Ag2H803, and 45C) provided the required data set to conduct this investigation. The methodology we followed, as well as assumptions of the models, have been described and discussed in detail elsewhere. ${ }^{21}$ We used $F k^{32}$ as our estimator of the standardized variance of allele frequency change and assumed that an average of 1 generation/month occurred for An. arabiensis on La Réunion, although this estimate might be strongly biased downwards. ${ }^{15}$ Computations were implemented by comparing allelic frequencies derived i) from the northwest population only as genotypic data from Simard and others ${ }^{22}$ were obtained from one An. arabiensis population sampled in this area ("Northwest population" in Table 3) and ii) from the pooled data set presented in this study to provide a conservative $\mathrm{Ne}$ estimate for the island population of $\mathrm{An}$. arabiensis ("Island population" in Table 3).

\section{RESULTS AND DISCUSSION}

In the current study, we explored extant genetic variability and its distribution within and between An. arabiensis mosquito populations sampled in three discrete locations on $\mathrm{La}$ Réunion island. Mosquito genotypes were determined from 125 An. arabiensis specimens: 50 originated from the northeast location, 53 from the southwest, and 22 from the northwest. We aimed at providing a clear and exhaustive description of the malaria vector's population structure on the island, as a prerequisite to assess feasibility and relevance of the implementation of innovative vector control measures based on population replacement/suppression through the release of genetically altered/sterilized mosquitoes. ${ }^{10}$

Genetic diversity within populations. Genetic diversity was assessed from allelic and genotypic frequencies observed at 10 microsatellite loci spread throughout An. arabiensis chromosomes (Table 1; Figure 2). All commonly used indices detected reduced genetic variability in our samples. The mean number of alleles per locus for the overall population was 3.0 and mean observed heterozygosity across all loci was 0.304 , ranging from 0.286 for the southwest (SW) population to 0.341 for the northwest (NW) population. There was no significant difference in either the mean number of alleles per locus nor in the mean observed heterozygosity between the
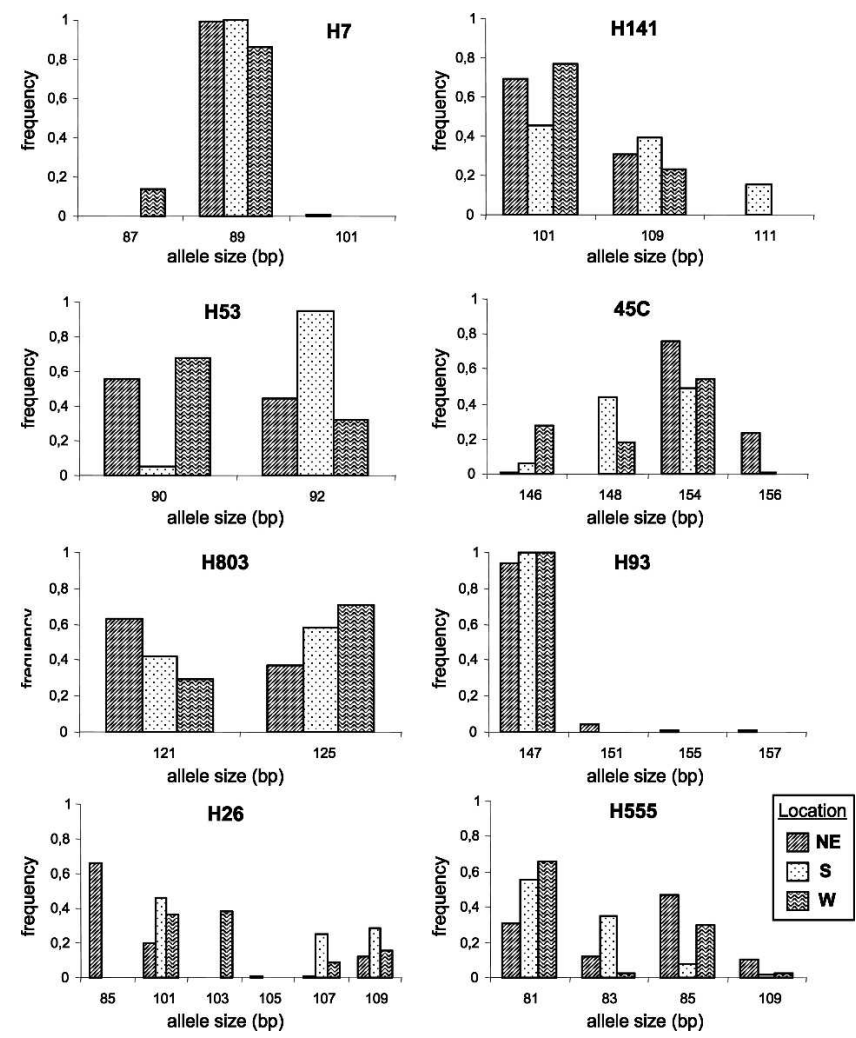

FIGURE 2. Allele frequencies at the 10 microsatellite loci used in the three mosquito populations. Alleles are given according to their observed size in base pairs (bp); Y axis represents the allele frequency in $\%$.

three populations we investigated (F-test on a one-way ANOVA: $\mathrm{F}>0.11 ; P>0.36)$. Two loci, AgXH49 and $\mathrm{Ag} 2 \mathrm{H} 325$, were fixed for the same allele in all specimens tested. All eight remaining loci showed low to moderate levels of polymorphism, with two to six alleles per locus and average observed heterozygosity across the entire population ranging from 0.049 for locus $\mathrm{Ag} 3 \mathrm{H} 93$ to 0.613 for locus Ag2H26. Locus AgXH49 is apparently fixed in all An. arabiensis populations tested so far from continental Africa and islands in the Indian Ocean, ${ }^{22}$ while it is highly polymorphic in the sibling species An. gambiae. ${ }^{33}$ Locus Ag2H325 was also found to be highly polymorphic in An. gambiae. ${ }^{33}$ These loci were originally designed from An. gambiae DNA and their use across species depends on sequence conservation in the sites of primer binding and maintenance of repeated arrays long enough to promote polymorphism..$^{34,35}$ Hence, the lack of polymorphism observed at both loci in our An. arabiensis samples might reflect a different molecular evolution for these loci in this species, rather than a population-specific pattern. ${ }^{24}$ This is not the case for the eight other loci we used in our study. For example, loci $\mathrm{AgXH7}$ and Ag2H26 revealed high polymorphism in continental An. arabiensis populations, showing up to 12 and 19 different alleles, respectively. ${ }^{21,22,36}$ Restricted allelic diversity in hypervariable loci together with low heterozygosity estimates, as observed in the current study, might therefore reflect small population size (see below). Reduced genetic variability in An. arabiensis from La Réunion has been reported with chromosomal $^{37}$ and other molecular markers ${ }^{38}$ as well strength- 
ening our finding. Girod and others ${ }^{37}$ demonstrated the paucity of chromosomal inversion polymorphism in An. arabiensis from La Réunion, where inversion $2 \mathrm{Rb}$ appeared as a fixed arrangement and inversion $3 \mathrm{Ra}$ occurred at a very low frequency of $4.7 \%$ in a sample of 76 chromosome complements observed. Similarly, Donnelly and others ${ }^{38}$ observed a single mtDNA-ND5 haplotype in their An. arabiensis sample from the island, although low sample size $(N=6)$ may have biased their results.

Hardy-Weinberg equilibrium and tests for linkage disequilibrium. Conformance to Hardy-Weinberg expectations and linkage disequilibrium between loci were assessed in each of the three geographical populations and overall. All loci conformed to Hardy-Weinberg expectation in all three populations, suggesting homogeneity of the gene pool at the local geographical scale (Table 1). Significant linkage disequilibrium was observed between locus $\mathrm{Ag} 2 \mathrm{H} 141$ and locus 45C in the northwest population only $(P<0.05)$. These results suggest random mating within each geographical population and validate our sampling design as no evidence for inbreeding was observed, despite all specimens being collected at their larval stage. However, when all samples were pooled and considered as belonging to a single population, strong and significant deficits in heterozygotes were observed for loci $\mathrm{AgXH} 53, \mathrm{Ag} 2 \mathrm{H} 26$, and 45C, as evidenced by positive and statistically significant Fis values (Table 1, overall). Linkage disequilibrium between loci was revealed in 5 out of 28 possible tests, after the sequential Bonferroni procedure was applied to take into account multiple tests. The most polymorphic locus, $\mathrm{Ag} 2 \mathrm{H} 26$, was involved in 4 of these occurrences. It is likely that some of the differences observed between the pooled and unpooled populations are the result of differences in sample sizes, but some disequilibrium may be due to differences in allele and genotype frequencies among populations large enough to cause a Wahlund effect. ${ }^{39}$ Altogether, our results suggest subdivision of the gene pool at the island level, although geographic An. arabiensis populations appear panmictic.

Differentiation between populations. Pairwise and overall Fst estimates are shown in Table 2, together with their statistical significance. Genotypic differentiation tests calculated for all population samples showed highly significant deviation from homogeneity at every locus (except for loci $\mathrm{AgXH} 49$ and $\mathrm{Ag} 2 \mathrm{H} 325$ that were fixed for the same allele in all populations), with an overall Fst estimate of $0.204\left(P<10^{-4}\right)$.

TABLE 2

Estimates of genetic differentiation $(F s t)$ between populations

\begin{tabular}{lcccc}
\hline \multicolumn{1}{c}{ Locus } & NE vs. SW & NE vs. NW & SW vs. NW & All \\
\hline AgXH7 & 0.0004 & $\underline{\mathbf{0 . 1 5 6 3}}$ & $\underline{\mathbf{0 . 1 9 9 1}}$ & $\underline{\mathbf{0 . 1 3 4}}$ \\
AgXH53 & $\underline{\mathbf{0 . 4 7 0 9}}$ & 0.0139 & $\underline{\mathbf{0 . 6 7 0 5}}$ & $\underline{\mathbf{0 . 4 2 5}}$ \\
Ag2H803 & $\underline{\mathbf{0 . 3 3 2 0}}$ & $\underline{\mathbf{0 . 3 4 5 5}}$ & $\underline{\mathbf{0 . 1 1 8 6}}$ & $\underline{\mathbf{0 . 2 8 9}}$ \\
Ag2H26 & $\underline{\mathbf{0 . 0 6 6 7}}$ & 0.0023 & $\underline{\mathbf{0 . 1 1 0 4}}$ & $\underline{\mathbf{0 . 0 6 8}}$ \\
Ag2H141 & $\underline{\mathbf{0 . 0 3 6 8}}$ & $\underline{\mathbf{0 . 1 7 1 7}}$ & $\underline{\mathbf{0 . 0 7 8 2}}$ & $\underline{\mathbf{0 . 1 8 9}}$ \\
45C & $\underline{\mathbf{0 . 1 7 5 6}}$ & $\underline{\mathbf{0 . 1 0 6 4}}$ & $\underline{\mathbf{0 . 1 1 8 9}}$ & $\underline{\mathbf{0 . 1 5 0}}$ \\
Ag3H93 & $\underline{\mathbf{0 . 2 3 0 7}}$ & $\underline{\mathbf{0 . 1 5 9 6}}$ & $\underline{\mathbf{0 . 1 8 6 5}}$ & $\underline{\mathbf{0 . 2 0 4}}$ \\
Ag3H555 &
\end{tabular}

, irrelevant because the same allele was fixed in both populations.
Fst estimates were calculated according to Weir and Cockerham ${ }^{28}$ and tested using permutation procedures with Arlequin (Schneider and others ${ }^{29}$ ). Significance thresholds were adjusted using the sequential Bonferroni procedure to account for multiple testing. Bolded values, $P<0.05$; bolded underlined values, $P<0.01$.
Furthermore, each of our three geographical populations appeared clearly differentiated from the others, with pairwise Fst estimates across all loci ranging from 0.160 between the northeast (NE) and northwest (NW) populations to 0.231 between the northeast (NE) and southwest (SW) populations. All polymorphic loci contributed to this amount of differentiation as most single locus $F$ st estimates were highly significant: only 5 out of 23 computable single locus pairwise Fst estimates were non-significant (Table 2). In addition, private alleles (i.e., alleles found in only one population) were observed in all three populations (Figure 2). Although sampling error and reduced sample size might increase occurrence of private alleles in subpopulations, their presence sometimes in high frequencies (allele 85 at locus Ag2H26 in the northeast population for example) indicates that gene flow between populations is too weak to allow homogenization of the gene pool. ${ }^{40}$ These results strengthen our findings of heterogeneity of the gene pool and suggest that gene flow is highly restricted between geographical populations of An. arabiensis on the island.

The high Fst estimates we obtained when compiling information from all microsatellite loci (Table 2, mean over all loci) are one order of magnitude higher than what has commonly been reported between continental An. arabiensis populations, sometimes separated by much larger geographical distances. ${ }^{22,36,41,42}$ However, Onyabe and Conn $^{43}$ reported Fst estimates in the range 0.196-0.258 between $A n$. arabiensis populations sampled across Nigeria. Although isolation by distance alone might explain their findings, the authors argued that difference in effective population size $(\mathrm{Ne})$ between local populations due to sequential founder effects in the most southern populations of An. arabiensis might have inflated genetic distance between populations. Enhanced random genetic drift due to population size limitation is indeed a major evolutionary force that counteracts the effect of both migration and mutation as a source of (neutral) genetic diversity, such that small isolated populations will rapidly drift apart. ${ }^{44}$ To further characterize the genetic structure of $A n$. arabiensis on La Réunion, we therefore explored issues relating to the effective population size.

Effective population size. Historical, demographic and genetic evidences suggest that the effective population size of An. arabiensis on La Réunion is low. They were extensively discussed by Simard and others ${ }^{22}$ and Girod and others ${ }^{37}$ and include strong founder effect during colonization of the island by anophelines species at the end of the 19 th century ${ }^{45}$ followed by intensive vector control during the 1950s until the island was declared free of malaria in 1979. However, relict An. arabiensis populations were still thriving in remote suitable ecological niches spread across the island. Malaria vector surveillance programs through breeding site monitoring, insecticide spraying in referenced vector development sites, harbors, and airports were then implemented to keep the island free of malaria and to avoid unintentional importation of foreign vector mosquitoes. ${ }^{15}$ As mentioned above, the paucity of genetic diversity observed in An. arabiensis populations from La Réunion in this and former studies $22,37,38$ is consistent with low effective population size. Furthermore, we generally observed large gaps in microsatellite allele arrays with a number of allele classes that were not represented (see Figure 2, loci AgXH7, Ag2H141, Ag2H26, and Ag3H555 in particular), as expected through stochastic allele loss due to 
enhanced random genetic drift in populations of small effective population size.

Calculation of quantitative estimates of the effective population size of the An. arabiensis population in La Réunion gave in both cases, the northwest population and the pooled data set, $\mathrm{Ne}$ estimates in the hundreds, with upper $95 \%$ confidence limits below 1,500 (Table 3). Longitudinal surveys of An. arabiensis abundance on La Réunion suggested that population size varies from one generation to the other. ${ }^{15}$ In this case, our $\mathrm{Ne}$ estimates will approximate the harmonic mean of each single-generation $\mathrm{Ne}$ and is therefore dominated by the smallest value. ${ }^{46}$ However, recent studies demonstrated that $\mathrm{Ne}$ estimates derived from such moment estimators are usually strongly biased upwards ${ }^{47,48}$ and that the true $\mathrm{Ne}$ is probably below the estimated values. Acknowledging these limitations, our results are consistent with evidence presented above for a restricted effective population size of An. arabiensis on the island.

Conclusion. Our study demonstrated strong genetic structuring between An. arabiensis populations on La Réunion, indicating the presence of barriers to gene flow. The high genetic differentiation observed within the island is the result of intensive and continued control measures that maintain reduced effective population size and prevent introduction of migrants. Nevertheless, a genetic adaptation to environment can not be precluded when considering the very different climatic patterns between the northeast, northwest, and southwest regions. This strong structuring situation represents an ideal framework for the prospect of implementing SIT-based control trials. Indeed, the small mosquito population densities on La Réunion would favor the success of a SIT operation, as the effective number of sterile males necessary for the release would be limited. Moreover, data gathered through decades of sustained entomological surveillance programs, including GPS-positionning of breeding sites and monitoring of their productivity, would provide an indication of the most appropriate release points. Multiple releases at different locations might indeed be required because of population isolation. We may wonder nevertheless if the strong genetic structure observed on La Réunion island could have effects on genetic control operations. For example, if mosquitoes to be released are engineered from a single colony, they would have different genotypic frequencies compared with the local natural populations and this could reduce their mating competitiveness and/or female fecundity, particularly if the observed structure is related to adaptation to local environements. The fact that An. arabiensis populations from the island still have the ability to cross mate with colonies from

TABLE 3

Effective population size $(\mathrm{Ne})$ estimates based on $F k$ computations $\left(\right.$ Pollak $\left.^{32}\right)$

\begin{tabular}{lccccccc}
\hline & \multicolumn{3}{c}{ Northwest population } & & \multicolumn{3}{c}{ Island population } \\
\cline { 2 - 3 } \multicolumn{1}{c}{ Locus } & $F k$ & $\mathrm{Ne}$ & $95 \% \mathrm{CI}$ & & $F k$ & $\mathrm{Ne}$ & $95 \%$ CI \\
\hline Ag2h141 & 0.1909 & 309 & {$[0-8,632]$} & & 0.0784 & 756 & {$[17-6,419]$} \\
Ag2H26 & 0.1897 & 311 & {$[19-1,717]$} & & 0.0886 & 654 & {$[94-2,347]$} \\
Ag2H803 & 0.0007 & Infinity & ND & & 0.1300 & 421 & {$[0-4,002]$} \\
45C & 0.1894 & 280 & {$[18-1,435]$} & & 0.0939 & 611 & {$[64-2,443]$} \\
All 4 loci & 0.1728 & 349 & {$[81-1,053]$} & & 0.0921 & 625 & {$[206-1,453]$} \\
\hline
\end{tabular}

Twelve generations a year was assumed. $95 \%$ confidence intervals shown in brackets were computed according to Eq. (11) in Waples. ${ }^{30}$ the African continent ${ }^{37}$ is a positive indication that, despite restricted gene flow between geographical populations, crossmatings between each population should be possible. But the establishment of an An. arabiensis colony originated from $\mathrm{La}$ Réunion would certainly represent an advantage. During the past decade, mosquito colony establishment has been improved, allowing mass production of quality insects. Because for malaria only female mosquitoes transmit parasites, females should be removed during mass production if insects have to be released. Genetic sexing method would then provide a large improvement relative to current methods. Researches are underway and the use of insect transformation technologies to develop transgenic approaches to sexing appears promising. ${ }^{49,50}$ If fitness and mating competitiveness of sterilized strains are efficient, SIT programs would then represent an interesting approach to characterize transgenic mosquito population biology in isolated environments. Indeed, dispersal and survival rates and mating capability of transgenic mosquitoes need to be determined before considering release of fertile modified mosquitoes.

Received March 5, 2005. Accepted for publication July 11, 2005.

Acknowledgments: We would like to thank the technical team in charge of vector surveillance and control on La Réunion island for help with larval collections. We acknowledge Maureen Coetzee, two anonymous reviewers, and the journal editor for their help in improving a former version of this paper.

Financial support: The authors thank the IRD-UR016 for financial support.

Authors' addresses: Isabelle Morlais and Frédéric Simard, Organisation de Coordination pour la lutte contre les Endémies en Afrique Centrale, BP 288, Yaoundé, Cameroon, Telephone: (+237) 223-2232, Fax: (+237) 223-0061 and Institut de Recherche pour le Développement (IRD), BP 1857, Yaoundé, Cameroon, Telephone: (+237) 2201508, Fax: (+237) 220-1854. Didier Fontenille, Laboratoire De Lutte Contre Les Insectes Nuisibles, Institut De Recherche Pour Le Développement, 911 Av Agropolis, BP 64501, 34394 Montpellier Cedex 5, France, Telephone: (+33) 467-043222, Fax: $(+33)$ 467-542044. Romain Girod, Institut de Médecine Tropicale du Service de Santé des Armées, Unité d'Entomologie Médicale, BP 46, 13998 Marseille Armées, France, Telephone: (+33) 491-150194, Fax: (+33) 491150184. Richard Hunt, Animal, Plant \& Environmental Sciences, University of the Witwatersrand, Johannesburg, South Africa, Telephone (+27) 11-386-6480, Fax: (+27) 11-386-6481.

Reprint requests: Isabelle Morlais, Institut de Recherche pour le Développement (IRD), BP 1857, Yaoundé, Cameroon, Telephone: (+237) 220-1508, Fax: (+237) 220-1854, E-mail: morlais@ird.fr.

\section{REFERENCES}

1. Gillies MT, Coetzee M, 1987. A supplement to the anophelinae of Africa south of the Sahara. Publ South Afr Inst Med Res 55: 143 pp.

2. Hunt RH, Coetzee M, Fettene M, 1998. The Anopheles gambiae complex: a new species from Ethiopia. Trans $R$ Soc Trop Med Hyg 92: 231-235.

3. Coetzee M, Craig M, le Sueur D, 2000. Distribution of African malaria mosquitoes belonging to the Anopheles gambiae complex. Parasitol Today 16: 74-77.

4. WHO. 2003. Africa malaria report 2003. Geneva: World Health Organization/UNICEF.

5. Amorosa LF, Corbellini G, Coluzzi M, 2005. Lessons learned from malaria: Italy's past and sub-Sahara's future. Health Place 11: 67-73.

6. Toure YT, Coluzzi M, 2000. The challenges of doing more against malaria, particularly in Africa. Bull World Health Organ 78: 1376.

7. Moreira LA, Ghosh AK, Abraham EG, Jacobs-Lorena M, 2002. 
Genetic transformation of mosquitoes: a quest for malaria control. Int J Parasitol 32: 1599-1605.

8. Coleman PG, Alphey L, 2004. Genetic control of vector populations: an imminent prospect. Trop Med Int Health 9: 433-437.

9. Varmus H, Klausner R, Zerhouni E, Acharya T, Daar AS, Singer PA, 2003. Public health. Grand challenges in global health. Science 302: 398-399.

10. Benedict MQ, Robinson AS, 2003. The first releases of transgenic mosquitoes: an argument for the sterile insect technique. Trends Parasitol 19: 349-355.

11. Dame DA, Jordan AM, 1981. Control of tsetse flies, Glossina spp. Adv Vet Sci Comp Med 25: 101-119.

12. Patterson RS, Weidhaas DE, Ford HR, Lofgren CS, 1970. Suppression and elimination of an island population of Culex pipiens quinquefasciatus with sterile males. Science 168: 1368-1370.

13. Hamon J, Dufour G, 1954. La lutte antipaludique à La Réunion. Bull WHO 11: 525-556.

14. Girod R, Salvan M, Denys JC, 1995. La lutte contre la réintroduction du paludisme à La Réunion. Cahier Santé 5: 397-401.

15. Girod R, Salvan M, Simard F, Andrianaivolambo L, Fontenille D, Laventure S, 1999. Evaluation of the vectorial capacity of Anopheles arabiensis (Diptera:Culicidae) on the island of Réunion: an approach to the health risk of malaria importation in an area of eradication. Bull Soc Pathol Exot 92: 203-209.

16. Gillies MT, De Meillon B, (1968). The Anophelinae of Africa south of the Sahara. Pub South Afr Inst Med Res 54: 202-220.

17. Morlais I, Ponçon N, Simard F, Cohuet A, Fontenille D, 2004. Intraspecific nucleotide variation in Anopheles gambiae: new insights into the biology of malaria vectors. Am J Trop Med Hyg 71: 795-802.

18. Scott JA, Brogdon WG, Collins FH, 1993. Identification of single specimens of the Anopheles gambiae complex by the polymerase chain reaction. Am J Trop Med Hyg 49: 520-529.

19. Zheng L, Benedict MQ, Cornel AJ, Collins FH, Kafatos FC, 1996. An integrated genetic map of the African human malaria vector mosquito, Anopheles gambiae. Genetics 143: 941-952.

20. Zheng L, Collins FH, Kumar V, Kafatos FC, 1993. A detailed genetic map for the $\mathrm{X}$ chromosome of the malaria vector, Anopheles gambiae. Science 261: 605-608.

21. Simard F, Lehmann T, Lemasson JJ, Diatta M, Fontenille D, 2000. Persistence of Anopheles arabiensis during the severe dry season conditions in Senegal: an indirect approach using microsatellite loci. Insect Mol Biol 9: 467-479.

22. Simard F, Fontenille D, Lehmann T, Girod R, Brutus L, Gopaul R, Dournon C, Collins FH, 1999. High amounts of genetic differentiation between populations of the malaria vector Anopheles arabiensis from West Africa and eastern outer islands. Am J Trop Med Hyg 60: 1000-1009.

23. Wang R, Kafatos FC, Zheng L, 1999. Microsatellite markers and genotyping procedures for Anopheles gambiae. Parasitol Today 15: 33-37.

24. Kamau L, Lehmann T, Hawley WA, Orago AS, Collins FH, 1998. Microgeographic genetic differentiation of Anopheles gambiae mosquitoes from Asembo Bay, western Kenya: a comparison with Kilifi in coastal Kenya. Am J Trop Med Hyg 58: 64-69.

25. Raymond M, Rousset F, 1995. GENEPOP (version 1.2): population genetics software for exact tests and ecumenicism. Journal of Heredity 86: 248-249.

26. Holm S, 1979. A simple sequentially rejective multiple test procedure. Scandinavian Journal of Statistics 6: 65-70.

27. Wright S, 1978. Variability within and among natural populations. In Evolution and Genetics of Populations., Vol. 4. Chicago: University of Chicago Press.

28. Weir BS, Cockerham CC, 1984. Estimating F-statistics for the analysis of population structure. Evolution 38: 1358-1370.

29. Schneider S, Kueffer JM, Roessli D, Excoffier L, (1997). Arlequin ver. 1.1: A software for population genetic data analysis. Genetics and Biometry Laboratory, University of Geneva.

30. Waples RS, (1991). Genetic methods for estimating the effective population size of cetacean populations. In Hoelzel, AR. Genetic Ecology of Whales and Dolphins. Cambridge, University Press, 279-300.
31. Waples RS, (1989). A generalized approach for estimating effective population size from temporal changes in allele frequencies. Genetics 121: 379-391.

32. Pollak E, 1983. A new method for estimating effective population size from allele frequency changes. Genetics 104: 531548.

33. Wondji C, Simard F, Fontenille D, 2002. Evidence for genetic differentiation between the molecular forms $\mathrm{M}$ and $\mathrm{S}$ within the Forest chromosomal form of Anopheles gambiae in an area of sympatry. Insect Mol Biol 11: 11-19.

34. Primmer CR, Moller AP, Ellegren H, 1996. A wide-range survey of cross-species microsatellite amplification in birds. Mol Ecol 5: $365-378$.

35. Forbes KJ, Fang Z, Pennington TH, 1995. Allelic variation in the Helicobacter pylori flagellin genes flaA and flaB: its consequences for strain typing schemes and population structure. Epidemiol Infect 114: 257-266.

36. Donnelly MJ, Townson H, 2000. Evidence for extensive genetic differentiation among populations of the malaria vector Anopheles arabiensis in eastern Africa. Insect Mol Biol 9: 357367.

37. Girod R, Coetzee M, Salvan M, Hunt RH, 2001. Chromosomal polymorphism of populations of Anopheles arabiensis (Diptera: Culicidae) from Reunion island and cross-fertility among continental African populations. Parassitologia 43: 99103.

38. Donnelly MJ, Pinto J, Girod R, Besansky NJ, Lehmann T, 2004. Revisiting the role of introgression vs shared ancestral polymorphisms as key processes shaping genetic diversity in the recently separated sibling species of the Anopheles gambiae complex. Heredity 92: 61-68.

39. Wahlund S, 1928. Composition of populations from the perspective of the theory of heredity. Hereditas 11: 65-105.

40. Slatkin M, 1985. Rare alleles as indicators of gene flow. Evolution 39: 53-65.

41. Kamau L, Mukabana WR, Hawley WA, Lehmann T, Irungu LW, Orago AA, Collins FH, 1999. Analysis of genetic variability in Anopheles arabiensis and Anopheles gambiae using microsatellite loci. Insect Mol Biol 8: 287-297.

42. Nyanjom SR, Chen H, Gebre-Michael T, Bekele E, Shililu J, Githure J, Beier JC, Yan G, 2003. Population genetic structure of Anopheles arabiensis mosquitoes in Ethiopia and Eritrea. $J$ Hered 94: 457-463.

43. Onyabe DY, Conn JE, 2001. Population genetic structure of the malaria mosquito Anopheles arabiensis across Nigeria suggests range expansion. Mol Ecol 10: 2577-2591.

44. Avise JC, 1994. Molecular markers, natural history and evolution. London: Chapman and Hall.

45. Julvez J, Mouchet J, 1994. Le peuplement culicidien des îles du sud-ouest de l'Océan Indien. L'action de l'homme dans l'importation des espèces d'intérêt médical. Ann Soc Entomol Fr 30: 391-401.

46. Taylor CE, Manoukis NC, 2003. Effective population size in relation to genetic modification of Anopheles gambiae sensu stricto. In, Takken W, Scott TW. Ecological Aspects for Application of Genetically Modified Mosquitoes. Dordrecht, The Netherlands: Kluwer Academic Publishers. p 133-146.

47. Berthier P, Beaumont MA, Cornuet JM, Luikart G, 2002. Likelihood-based estimation of the effective population size using temporal changes in allele frequencies: a genealogical approach. Genetics 160: 741-751.

48. Tallmon DA, Luikart G, Beaumont MA, 2004. Comparative evaluation of a new effective population size estimator based on approximate bayesian computation. Genetics 167: 977988.

49. Thomas DD, Donnelly CA, Wood RJ, Alphey LS, 2000. Insect population control using a dominant, repressible, lethal genetic system. Science 287: 2474-2476.

50. Heinrich JC, Scott MJ, 2000. A repressible female-specific lethal genetic system for making transgenic insect strains suitable for a sterile-release program. Proc Natl Acad Sci USA 97: 82298232. 